\title{
Impairment of fixed-interval responding during chronic alcohol drinking in rats
}

\author{
JOHN H. McDONOUGH, JOHN H. GILL, and HAROLD C. NIELSON \\ University of Utah, Salt Lake City, Utah 84112
}

\begin{abstract}
Rats housed either in activity wheels or in standard cages were placed on a restricted feeding schedule and trained in operant chambers to respond on an FI-40 schedule for sugar-water rewards. When body weights and FI responding were stable, half of the subjects in each housing condition received both water and a $10 \%$ beer-ethanol solution ad lib for the next 30 days while the remaining subjects continued to receive water as their sole fluid. Subjects offered alcohol, irrespective of housing condition, drank a mean of $9.9 \mathrm{~g} / \mathrm{kg} / \mathrm{day}$ during the 30 days and showed shifts in the distribution of their responses within the fixed intervals. Reliable changes also occurred in measures of body weight, water intake, and activity for subjects that consumed alcohol.
\end{abstract}

A major difficulty in using animals to simulate the human alcoholic is getting the animals to drink alcohol voluntarily in a choice situation. Because of this difficulty, the investigation of behaviors that may accompany voluntary consumption of alcohol is not frequently reported. Although chronic intoxication in rats can be maintained, even to the point of establishing physical dependence if the rats are food deprived and offered alcohol as a caloric supplement. their alcohol consumption is not voluntary since they are offered no other source of food or fluid (Branchey, Raucher, \& Kissin, 1971; Mello, 1973). However, rats may drink alcohol voluntarily, with water also available, to gain additional alories in a situation where body weight loss is "self-imposed." A self-imposed loss of body weight, even to the point of starvation, has been described by Routenburg (1968), and by Routenburg and Kuznesof (1967) when rats that lived in activity wheels were placed on a $23.5-\mathrm{h}$ food-deprivation schedule. Instead of reducing their activity to prevent additional losses of body weight, the rats increased running activity and lost additional weight that could not be compensated for during the 30 min of feeding. Since rats will drink alcohol as a caloric supplement, and since they self-impose a weight loss to the point of starvation when housed in activity wheels and are restricted to a $23.5-\mathrm{h}$ feeding schedule, it may be that if the rats were provided

This research was supported by Contract DADA 17-73-C-3058 from the U.S. Army Medical Research and Development Command. In conducting the research described in this report, the investigators adhered to the "Guide for Laboratory Animal Facilities and Care," as promulgated by the Committee on Revision of the Guide for Laboratory Animal Facilities and Care of the Institute of Laboratory Animal Resources, National Academy of Science-National Research Council. J. H. McDonough is now at Biomedical Laboratories, Edgewood Arsenal, Maryland 21010. Requests for reprints should be addressed to Dr. H. C. Nielson, who is now at the Department of Psychology, University of Utah, Salt Lake City, Utah 84112. continuous access to alcohol under these circumstances they would increase the quantity of alcohol they consume and thereby offset the "self-imposed" losses of body weight from increased running. It then would be possible to observe effects of the increased alcohol consumption upon concurrent behaviors. The present experiment was conducted to determine whether housing in activity wheels would effect chronic alcohol consumption differentially in rats, and if so, whether it would alter their performance of an operant (FI-40) task.

\section{METHOD}

\section{Subjectu}

Twenty adult male rats of the Wistar strain were used as subjects. The rats lived in group cages with ad-lib access to food and water prior to being assigned to groups.

\footnotetext{
Apparatus

Wahman activity wheels or standard laboratory rack cages were used to house individual subjects. The activity wheels and cages were located in separate rooms, which were kept at temperatures of $70^{\circ}-72^{\circ} \mathrm{F}$ and maintained on a normal 12-h light-dark cycle. Food (powdered Wayne Lab-Blox) was offered in stainless steel feeding cups, and sheets of paper were placed under the cages to catch spillage. Water and alcohol solutions were presented in baby bottles that were corked with rubber stoppers containing a stainless steel drinking tube with steel balls inside the tube to retard drippage. When water alone was offered, the drinking spout was positioned in the middle of the cage; when a choice of solutions was offered, the spouts were adjacent and their positions were alternated every day. Drippage was controlled by placing a bottle of each fluid on an empty cage and subtracting the amount lost from each subject's daily intake.

The operant conditioning chambers were Plexiglas compartments with evenly spaced brass rods serving as the floor. A single Plexiglas lever was mounted on the left side of one wall, and it protruded into the chamber approximately $2.5 \mathrm{~cm}$. Over this lever was a small pilot light covered with a jewel cap which was illuminated briefly during each leverpress. Located on the right side of this same wall was a recessed hole, $3.5 \mathrm{~cm}$ in diam, which contained a dipper that delivered a $0.1-c c$ droplet of a $30 \%(w / v)$ sucrose solution. The chambers were housed in noise-attenuating boxes, each diffusely illuminated with a $20-\mathrm{W}$ soft-light bulb and provided with a fan for frequent air exchange. The fans and white
} 
noise in the experimental room masked extraneous sounds. The chambers were programmed electromechanically from equipment in a separate room.

\section{Procedure}

The subjects were assigned randomly to one of four groups. In Group W-NA (wheel-no alcohol. $N=6$ ), the subjects lived in activity wheels and received no alcohol during the experiment; the subjects in Group W-A (wheel-alcohol. $\mathrm{N}=6$ ) also were housed in activity wheels but were offered a $10 \%(\mathrm{v} / \mathrm{v})$ beer-ethanol solution ad lib during the 30 -day period of chronic drinking. The subjects in Group C-NA (cage-no alcohol. $N=4$ ) were housed in rack cages and received no alcohol, while the subjects in Group C-A (cage-alcohol. $N=4$ ) were housed in rack cages and offered the $10 \%$ alcohol solution during the period of chronic drinking.

All subjects were allowed free access to food and water for 1 week during which time daily records were made of body weight, food intake. water intake. and, for subjects that lived in wheels. activity (total revolutions). Each subject also received at least three 15 -min sessions in his operant conditioning chamber to familiarize him with the sights and sounds of the chamber prior to the initiation of barpress training.

All subjects then were placed on a 23.5-h restricted feeding schedule. which continued throughout the remainder of the

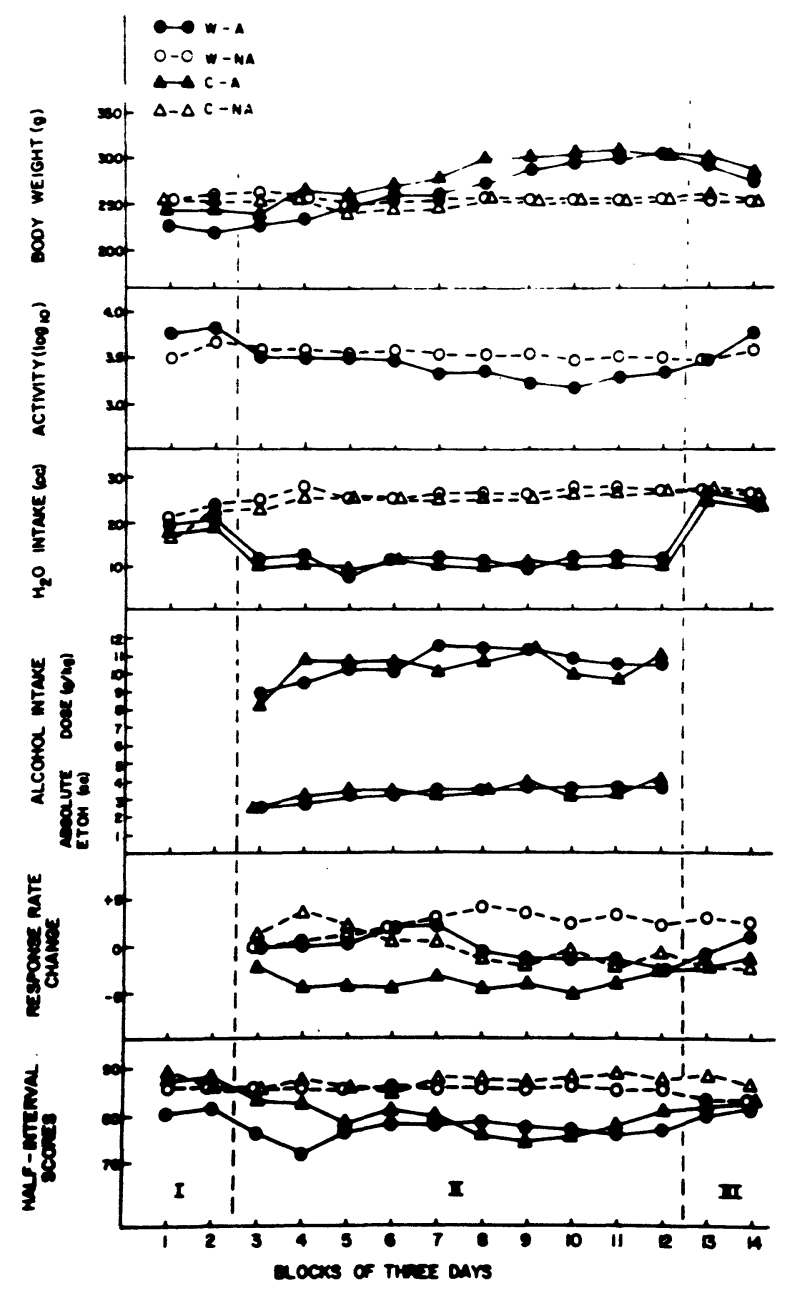

Figure 1. Three-day block means of body weights, activity scores, water and alcohol consumption, and operant performance data for experimental groups across baseline (I), alcohol (II), and postalcohol (III) phases. experiment, and were magazine trained during four $15-\mathrm{min}$ sessions. where they received 5-sec noncontingent presentations of the dipper on a random 15 -sec schedule. Next. noncontingent rewards were discontinued and subjects were shaped gradually to press the lever for rewards. initially with each response rewarded, and then on an FI 40-sec schedule. Each subject received a 15-min session each day $1 \mathrm{~h}$ prior to his daily 30 -min feeding period in the home cage. Daily records were kept of total leverpresses, separated into total responses in each half of the $40-\mathrm{sec}$ intervals, and total rewards earned.

Upon initiating restricted feeding, the subjects in all groups immediately began to lose weight. with extreme losses occurring among W subjects. As subjects approached $60 \%$ of predeprivation weights. they were given additional time to feed to maintain their weights at this level. Because of the rapid weight loss of the $W$ subjects, a more severe feeding schedule then was imposed on $C$ subjects so that body weight loss was equivalent across groups before alcohol was introduced. When weights stabilized, Phase I (baseline) operant performance data were obtained for 6 consecutive days. During Phase I, the subjects were required to place at least $67 \%$ of their total daily responses within the second halves of the 40-sec intervals. This criterion was established to ensure that each subject was responding in a manner characteristic of FI schedules before alcohol was introduced.

On the day that every subject of both $W$ groups or both $C$ groups achieved Phase I criterion performance, Phase II of the experiment began. During the 30 days of Phase $\Psi$, the subjects to receive alcohol, Groups W-A and C-A, were offered a choice of $10 \%(v / v)$ beer-ethanol solution or water. The alcohol solution was prepared fresh daily by adding $95 \%$ USP ethanol to decarbonated $3.2 \%$ beer to raise the alcohol content to $10 \%$ (v/v). Throughout Phase II, each subject in Groups W-A and W-NA continued to receive 30 -min access to food each day, along with supplements where appropriate, while subjects in Groups C-A and C-NA were allowed the same amount of time to eat that they had received during Phase I. All subjects continued to receive a daily session in the conditioning chambers with the FI 40 -sec schedule in effect.

At the end of 30 days. alcohol was discontinued and all subjects again received water as their sole fluid. Daily sessions in the conditioning chambers were continued for the following 6 days (Phase III).

\section{RESULTS}

Figure 1 presents mean body weights, activity scores. water and alcohol consumption, and operant performance data for treatment groups across the three experimental phases. The data were evaluated by repeated-measures analyses of variance for unequal cell frequencies (unweighted-means solution) (Winer. 1971) that differentiated housing conditions (W is. C). drinking conditions (A is. NA), and experimental phases (I is. II is. III). Predeprivation results are described when they were included in the analyses. Individual comparisons were run using Duncan tests. The blocks-of-days source was included only in the analysis of alcohol consumption data to simplify the remaining analyses and since preliminary analyses of the remaining data had shown findings comparable to those presented here.

\section{Body Weight}

Body weight means for each group are presented in Panel A of Figure 1. Analysis of predeprivation body weights revealed no reliable between-group differences. The imposition of restricted feeding resulted in 
approximately a $40 \%$ body weight loss for all subjects by the time Phase I began. The analysis-of-bodyweight scores revealed reliable sources for phases $[\mathrm{F}(2,32)=14.3, \mathrm{p}<.01]$ and the Drinking Conditions by Phases interaction $[\mathrm{F}(2,32)=26.96$, $p<.01]$. The comparison of means within the interaction showed that in Phase $I$, A subjects weighed less than did NA subjects $(p<.05)$. However, during Phase II, when A subjects had the opportunity to freely consume the beer-ethanol solution, A subjects weighed more than they did in Phase I $(p<.01)$ and their weights also were greater than were the weights of NA subjects during that phase $(p<.01)$. That alcohol served a caloric function for $A$ subjects may be inferred from the finding that the weights of A subjects then were less during the 6 days of Phase III when alcohol was withheld than they were during Phase II $(p<.05)$. The weights of NA subjects did not differ across phases.

\section{Activity}

Activity scores of W subjects were transformed to logs (base 10), and their means are presented in Panel B of Figure 1. Analysis of the data revealed a reliable Drinking Conditions by Phases interaction $[F(2.20)=11.20, p<.01]$. Individual comparisons showed that W, A subjects' activity was less during Phase II than it had been during Phase I or than it was during Phase III (ps <.01), and was less than the activity of W, NA subjects during any of the experimental phases (ps <.05). Phase I and Phase III performances of $\mathrm{W}, \mathrm{A}$ subjects did not differ. There was a reliable Drinking Conditions by Blocks of Days interaction $[F(11,110)=45.47$, $p<.01]$, and the evaluation of the mean differences revealed one noteworthy finding not covered in the main analysis: Differences between groups occurred during Blocks 6 through 12, where W, A subjects ran less than W, NA subjects (ps $<.01$ ); but by the last block of days within Phase III, W, A subjects were running more than were $W, N A$ subjects $(p<.01)$.

\section{Water Intake}

The water intake data are presented in Panel $\mathrm{C}$ of Figure 1. The analysis showed only a reliable Drinking Conditions by Phases interaction $[\mathrm{F}(2,32)=$ 4.85, $\mathrm{p}<.01]$. Individual comparisons of the means within this interaction showed that A subjects drank less water during Phase II than they did during either Phase I or Phase III (ps <.01), and their intake of water during Phase II also was less than that of NA subjects during any of the experimental phases (ps $<.01$ ). There were no reliable differences between A subjects and NA subjects during Phase I or Phase III, and there were no reliable differences within NA subjects' water intake across phases.

\section{Alcohol Intake}

Both mean alcohol-dose consumption data $(\mathrm{g} / \mathrm{kg})$ and the mean intake of absolute alcohol consumed per day for the 30 days of Phase II are presented in Panel D of Figure 1. The blocks-of-days source was evaluated in the analyses of these data, and it was the only reliable source from the analysis of dose consumption $[F(9,72)=2.52, p<.05]$. Individual comparisons of means from this source showed only that dose consumption of alcohol during the first block of Phase II was less than it was during any of the remaining blocks of days (ps $<.05$ and .01), which, themselves, did not differ. Analysis of absolute alcohol intake showed that there were no differences on this measure either between groups or across blocks of days. Neither analysis revealed any differential effect of housing conditions on alcohol consumption. A subjects drank a mean of $9.9 \mathrm{~g} / \mathrm{kg} / \mathrm{day}$ throughout the 30 days of Phase II.

\section{FI Performance}

An analysis of the barpress rates (responses/min) showed reliable differences between $A$ and NA subjects during Phase I. Hence, a mean barpress rate was calculated from each subject's Phase I performance, and difference from Phase I scores were determined across blocks of days for Phases II and III. These difference scores are shown in Panel E of the figure. The analysis-of-change scores showed no reliable effects either among main sources or within their interactions.

Half-interval scores (percent of total responses placed in the second halves of the intervals) also were calculated for each subject, and the group means are presented in Panel $F$ of Figure 1. The analysis of these scores showed both a reliable phases effect $[\mathrm{F}(2,32)=5.89, \mathrm{p}<.01]$ and a reliable Drinking Conditions by Phases interaction $[\mathrm{F}(2,32)=5.48$, $\mathrm{p}<.01$ ]. Individual comparisons of means within the Drinking Conditions by Phases interaction showed that there were no between group differences during Phase I; but during Phase II, A subjects showed a reduction in half-interval percentages to a level that was less than their percentages in Phase $I(p<.01)$ and also was less than the half-interval percentages of NA subjects during Phase II $(p<.01)$. During Phase III, the half-interval scores of $A$ subjects showed an increase from their Phase II performances $(p<.01)$ to a level that was no longer different from their Phase I performances, yet the Phase III percentages of $A$ subjects still were less than were those of NA subjects during Phase III ( $p<.05)$. The half-interval percentages of NA subjects showed no reliable changes across phases.

The mean-total responses placed in each half of the intervals during Phases I and II for NA and A subjects, irrespective of housing condition, were evaluated with a repeated-measures analysis of variance to determine whether the reduction in response percentages had been specific to a reduction in the second halves of the intervals or to an increase in the first halves, or to both. This analysis showed a 
reliable Drinking Conditions by Phases by Half-Intervals interaction $[F(1.18)=6.12, p<.05]$, and the individual mean comparisons showed that the A subjects had emitted fewer responses in the second halves of the fixed intervals during Phase II than during Phase $I(p<.05)$, whereas their responding during the first halves had not changed.

\section{Rewards Earned}

Analysis of mean total rewards earned per session during the three phases revealed reliable effects ( $\mathrm{df}=$ $2 / 32, p<.01)$ for phases $(F=8.57)$, Housing Conditions by Phases $(F=8.53)$, and the Drinking Conditions by Phases $(F=8.55)$ interactions. Individual comparisons of means within the Housing Conditions by Phases source showed that $\mathrm{C}$ subjects earned fewer rewards during Phase II than during either Phase I or Phase III ( $p s<.05)$, and this was fewer than the rewards earned by $W$ subjects in any of the three phases ( $p s<.05)$. There were no differences between rewards earned by $\mathrm{C}$ and $\mathrm{W}$ subjects in Phase I or Phase III. The Duncan test of the Drinking Conditions by Phases interaction showed that A subjects earned fewer rewards than did NA subjects during Phase II $(\mathrm{p}<.05)$. but there were no differences between these groups during Phase I or Phase III. NA subjects themselves showed no reliable differences in rewards earned across phases.

\section{DISCUSSION}

The daily consumption of $9.9 \mathrm{~g} / \mathrm{kg}$ of alcohol both by subjects whose weights were reduced experimentally and by subjects whose weight losses largely were "self-imposed" attests to the effectiveness of the present procedures for producing sustained high levels of alcohol consumption by rats in a free-choice situation. This daily alcohol intake is equivalent to doses that are reported to produce long-term learning deficits in rats or mice following 3-9 months of drinking when alcohol is incorporated into liquid diets (Freund, 1970; Freund \& Walker, 1971; Walker \& Freund, 1971, 1973). In addition, this level of alcohol consumption by A subjects was associated with reliable changes in their body weights, activity, water intake, and FI-40 performances, which shows that the alcohol consumption levels were sufficient to affect both measures of behavioral and physiological functioning.

The concept of "self-imposed" body-weight loss is used here to describe the procedure where additional body weight is lost beyond what is consequent to the limits of the food-deprivation schedule alone. Food deprivation itself is sufficient to produce increased alcohol consumption. and it would be incorrect to label the current procedure as strictly voluntary. However. the concern of the present experiment was whether additional, "self-imposed" losses of weight would result in additional alcohol ingestion that, in turn, would affect performance of an operant task. The procedure was highly effective in producing severe weight losses as well as increased consumption of alcohol. Indeed, it became necessary to impose a more severe restriction on the feeding of $C$ subjects to provide some assurance of comparable levels of deprivation prior to barpress training and testing. Hence, the failure to observe differences between the alcohol consumption of $\mathrm{C}$ and $\mathrm{W}$ subjects, where increased weight losses were externally imposed vs. "self-imposed," was significant since the procedure did provide a method for producing high levels of alcohol consumption. sufficient to affect operant performance, without the external imposition of a severely restricted feeding schedule.

The finding that the chronic alcohol drinking had no effect on A subjects' barpress rates is consonant with the findings of Freed (1972) that acutely self-intoxicated rats were not different from nonintoxicated control subjects in their rate of responding on an FI-60 schedule. The results of our half-interval data point to a more specific effect of chronic alcohol drinking on FI performance. Responses emitted on a well-learned FI schedule typically are spaced such that the greatest number occur in the period just prior to the interval limit (Dews. 1970). A subjects reduced the number of their responses placed on the second halves of the intervals during Phase II, and this resulted in a more even distribution of responses throughout the intervals. That A subjects may have been impaired in their ability to judge the interval limit is consistent with previous research showing that either chronic alcohol drinking or acute administration of high doses of alcohol impairs responding on schedules that differentially reinforce low rates (DRL), a schedule which also requires the animal to judge an interval limit (Gethens, Hawkins, \& Schrot, 1973; Sanders \& Pilley, 1973; Walker \& Freund, 1973). The change in response patterning by our $A$ subjects while drinking alcohol also was associated with a reliable reduction in the number of rewards they earned during the daily FI sessions. This result further substantiates reduced efficiency in these rats' performance and is consistent with the finding (Freed, 1972) that acutely self-intoxicated rats were less efficient (i.e., they earned fewer rewards per session) than were nonintoxicated rats even though both groups had responded at equivalent rates on an FI-60 schedule.

In this experiment, a procedure was used in which reductions in the body weights of rats, which contributed to their consumption of alcohol, was not entirely imposed by the experimenter. Rather, the restriction of access to food by the experimenter plus the failure of the rat to reduce his activity both contributed to losses of body weight and increased alcohol consumption. Hence, this experiment only partially meets the requirement for high-level and strictly voluntary consumption of alcohol that is 
thought to be necessary for an animal model of the human alcoholic (Lester \& Freed, 1973). However, further variations in this method, such as improving the taste of the alcohol beverage, may produce greater consumption of alcohol on a "voluntary" basis and provide yet a closer approximation of the human alcoholic condition.

There is no question that a better animal model of alcoholism would provide a basis for expanding our knowledge of the human alcoholic. However, we believe that the requirement of injestion of alcohol without food deprivation, usually demanded of an animal model, is included so that withdrawal symptoms, when and if they occur, are attributable to the consumption of alcohol per se and not to a nutritional deficit. Furthermore, we are not convinced that alcoholism in the absence of nutritional deficits is true even of the human condition. Mello and Mendelson (1970) report that alcoholic patients sometimes stop eating with an intention to increase the effect of the alcohol. This intention may have a basis in the fact that a reduction in caloric intake has been associated with a decreased rate of metabolism of alcohol (Mendelson, 1970). In addition, Mello (1972) suggests that human alcoholics may stop eating to increase blood alcohol levels as a means of combating tolerance. While the relationship between food and alcohol is a complex one, we see no reason to adhere rigidly to the position that the experimental animal must not be food deprived.

\section{REFERENCES}

Branchey, M., Raucher, G., \& Kissin, B. Modifications in the response to alcohol following the establishment of physical dependence. Psychopharmacologia (Berlin), 1971, 22, 314-322.

DEwS, P. B. The theory of fixed-interval responding. In W. N. Schoenfield (Ed.), The theory of reinforcement schedules. New York: Appleton-Century-Crofts, 1970. Pp. 43-61.

FREED, E. X. Alcohol and conflict: The role of self-intoxication in punishment discrimination by rats. Quarterly Journal of Studies on Alcohol, 1972, 33, 756-768.
FREUND, G. Impairment of shock avoidance learning after long-term alcohol ingestion in mice. Science, 1970, 168, 1599-1601.

Freund, G., \& WALKer, D. W. Impairment of avoidance learning by prolonged ethanol consumption in mice. Journal of Pharmacology and Experimental Therapeutics, 1971, 179, 284-292.

Gethens, S. H., Hawkins, T. D., \& Schrot, J. DRL scheduleinduced alcohol ingestion. Physiological Psychology, 1973, 1, $397-400$.

Lester, D., \& Freed, E. X. Criteria for an animal model of alcoholism. Pharmacology Biochemistry and Behavior, 1973, 1, 103-107.

Mello, N. K. Behavioral studies of alcoholism. In B. Kissin \& H. Begleiter (Eds.), The biology of alcoholism (Vol. 2), Physiology and behavior. New York: Plenum Press, 1972. Pp. 219:291.

Mello, N. K. A review of methods to induce alcohol addiction in animals. Pharmacology Biochemistry and Behavior, 1973, 1, 89-101.

Mello, N. K., \& Mendelson, J. H. Experimentally induced intoxication in alcoholics: A comparison between programmed and spontaneous drinking. Journal of Pharmacology and Experimental Therapeutics, 1970, 173, 101-116.

Mendelson, J. H. Biological concomitants of alcholism. New England Journal of Medicine, 1970, 283, 24-32, 71-81.

ROUTTENBERG, A. "Self-starvation" of rats living in activity wheels: Adaptation effects. Journal of Comparative and Physiological Psychology, 1968, 66, 234-238.

Routtenberg, A., \& Kuznesof, A. W. Self-starvation of rats living in activity wheels on a restricted feeding schedule. Journal of Comparative and Physiological Psychology, 1967, 64, 414-421.

Sanders, S. H., \& Pilley, J. Effects of alcohol on timing behavior in rats. Quarterly Journal of Studies on Alcohol, $1973,34,367-372$.

WALKer, D. W., \& FreUND, G. Impairment of shuttle box avoidance learning following prolonged alcohol consumption in rats. Physiology and Behavior, 1971, 7, 773-778.

WALKER, D. W., \& FREUND, G. Impairment of timing behavior after prolonged alcohol consumption in rats. Science, 1973, 182, 597-599.

WINER, B. J. Statistical principles in experimental design. New York: McGraw-Hill, 1971.

(Received for publication March 4, 1975; revision received July $1,1975$. 